\title{
ORIGINAL ARTICLE \\ Detrusor botulinum toxin A injection significantly decreased urinary tract infection in patients with traumatic spinal cord injury
}

\author{
C Jia ${ }^{1,2}$, L-M Liao ${ }^{1,2}$, G Chen $^{1}$ and Y Sui ${ }^{3}$
}

Study design: The study was designed as a single-arm clinical trial.

Objectives: To investigate the effect of detrusor botulinum toxin A (BoNTA) injection on urinary tract infection (UTI) in patients with spinal cord injury (SCl).

Setting: The study was performed in a national rehabilitation research center of China.

Methods: Between September 2010 and May 2012, 41 male inpatients with neurogenic detrusor overactivity (NDO) caused by traumatic SCI, mean age $36.0 \pm 8.8$ years, duration of SCl since inclusion $21.5 \pm 17.3$ months, received an injection of $300 \mathrm{U}$ BoNTA into detrusor. Before and 3 months after injection, each patient kept a bladder diary, underwent video-urodynamic investigation and urine culture. All UTIs occurring in the 6 months before and the 6 months after injection were recorded.

Results: Before injection, the mean number of UTI over 6 months was $1.39 \pm 1.36$. After injection, the mean significantly decreased to $0.78 \pm 0.96(P=0.023)$. The mean maximum detrusor pressure during filling decreased significantly in the patients of detrusor

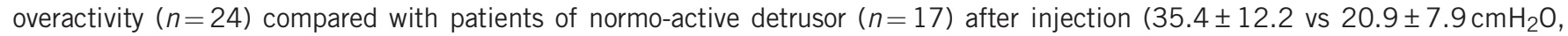
$P=0.000)$, meantime, the decrease of UTI was significant in the former $\left(1.29 \pm 1.21\right.$ vs $\left.0.41 \pm 0.62 \mathrm{cmH}_{2} \mathrm{O}, P=0.015\right)$ while no significant in the latter $(1.46 \pm 1.47$ vs $1.04 \pm 1.08, P=0.319)$.

Conclusion: Detrusor BoNTA injection significantly decreased UTI in SCI patients with NDO. This effect seems to be related to the decrease of detrusor pressure.

Spinal Cord (2013) 51, 487-490; doi:10.1038/sc.2012.180; published online 29 January 2013

Keywords: botulinum toxin; urinary tract infection; spinal cord injury; neurogenic detrusor overactivity

\section{INTRODUCTION}

Urinary tract infection (UTI) is the most common medical complication after spinal cord injury (SCI). ${ }^{1-3}$ Neurogenic detrusor overactivity (NDO), elevated intravesical pressure, reflux, elevated post void residuals, commonly found in SCI population, increase the risk of UTI. ${ }^{4,5}$ Detrusor botulinum toxin A (BoNTA) injection is an effective method to treat NDO and decrease detrusor pressure, ${ }^{6-9}$ but whether this method can suppress UTI is still in dispute and there was rare report. ${ }^{7,8,10}$

In this study, we explored the relationship between UTI and detrusor BoNTA injection in male inpatients with NDO caused by SCI.

\section{MATERIALS AND METHODS}

Between September 2010 and May 2012, this study was carried out in 41 male inpatients with NDO caused by traumatic SCI in a national rehabilitation research center of China. The patients' mean age was 36.0 \pm 8.8 (18-53) years and duration of SCI since inclusion was $21.5 \pm 17.3$ (3-87) months. Completeness of injury was defined according to the American Spinal Injury Association impairment scale, in which complete and incomplete injuries correspond to classes A and B to D, respectively. ${ }^{11}$ The severity of injury for
SCI patients treated with detrusor BoNTA injection is presented in Table 1. Before detrusor BoNTA injection, all patients had detrusor overactivity and incontinence, but they were either resistant to anticholinergic medications, or had discontinued treatment because of adverse effects. 32 patients were treated with anticholinergics of tolterrodine before inclusion and they continued the drugs during the study. All patients emptied by sterile intermittent catheterization and no one received preventive treatment for urinary infections during the study except intravenous Cefminox sodium $2.0 \mathrm{~g}$ half an hour before the operation of BoNTA injection and repeated once $4 \mathrm{~h}$ after injection, following $2.0 \mathrm{~g}$ twice daily for 2 days. Patients with urinary stones, vesicoureteral reflux, diabetes mellitus, chronic bronchitis or psychiatric comorbidities before inclusion were excluded.

UTI was defined as a colony count of $10^{5}$ colony-forming units per milliliter or greater, with a fever of $38^{\circ} \mathrm{C}$ and two symptoms including, over distention of the bladder, lower abdominal pain, increased urinary incontinence, increased spasticity, autonomic hyperreflexia and increased sweating or malaise. ${ }^{12,13}$ 'over distention of the bladder' was interpreted as 'uncomfortable distention of the bladder' here.

Two weeks before inclusion, all patients kept a voiding diary for 3 days, and underwent urine culture, ultrasound examination of the kidneys and bladder, 24-h creatinine clearance and video-urodynamic investigation according to the guidelines of the International Continence Society, ${ }^{14,15}$ and special attention

${ }^{1}$ Department of Urology, China Rehabilitation Research Center, Beijing, China; ${ }^{2}$ School of Rehabilitation Medicine, Capital Medical University, Beijing, China and ${ }^{3}$ Department of Pathology, China Rehabilitation Research Center, Beiijing, China

Correspondence: Professor L-M Liao, Department of Urology, China Rehabilitation Research Center and School of Rehabilitation Medicine, Capital Medical University, no. 10 Jiaomen Beilu, Fengtai District, Beijing 100068, China.

E-mail: Imliao@263.net

Received 20 September 2012; revised 9 December 2012; accepted 26 December 2012; published online 29 January 2013 
Table 1 The severity of injury for $\mathrm{SCl}$ patients treated with detrusor BoNTA injection

\begin{tabular}{lc}
\hline Variable & Value (no.) \\
\hline C2-6(AIS: A/B/C/D) & $2 / 4 / 3 / 0$ \\
T1-6(AIS: A/B/C/D) & $6 / 2 / 0 / 0$ \\
T7-12(AIS: A/B/C/D) & $13 / 2 / 4 / 0$ \\
L1-5(AIS: A/B/C/D) & $3 / 1 / 1 / 0$
\end{tabular}

Abbreviations: AIS, American Spinal Injury Association Impairment Scale grade; BoNTA,

botulinum toxin $\mathrm{A} ; \mathrm{SCl}$, spinal cord injury.

was given to the following variables: maximum detrusor pressure during filling, bladder compliance, maximum cystometric capacity.

For 6 months between inclusion and detrusor BoNTA injection, the nurses of the center measured axillary temperature for 2 times daily with standard mercury thermometers. The number of measurements was increased during febrile periods. Axillary temperature over $38.0^{\circ} \mathrm{C}$ was regarded as elevated. An increase in axillary temperature at least twice in $24 \mathrm{~h}$ was considered fever. In case of suspicion of UTI, a complete physical examination was performed by a neurourologist in all cases, then urinalysis and urine culture were performed. The antibiotic treatment received and its duration were recorded when UTI occurred.

All patients underwent a fixed procedure of detrusor BoNTA injection in the operating room using a rigid cystoscopy and a flexible injection needle with/without general anesthesia after 6 months enrolled the study. BoNTA (300 U; BTX-A, Lanzhou Biological Products, China) was dissolved in $15 \mathrm{ml}$ normal saline and was injected into the detrusor at 30 different sites (10 units of BTX-A in $0.5 \mathrm{ml}$ normal saline, per site), sparing the trigone.

Three months after injection, the patients kept a voiding diary for 3 days, underwent urine culture, video-urodynamic investigation according to International Continence Society guidelines and ultrasound examination of the kidneys and bladder. For 6 months after injection, axillary temperature was measured twice daily by nurses of the center. In case of suspicion of UTI, a complete physical examination, urinalysis and urine culture were performed as before injection. The antibiotics and its duration were also recorded when UTI occurred.

SPSS16.0 for Windows (SPSS, Chicago, IL, USA) was used for statistics. Results of video-urodynamic investigation and urine culture were analyzed by mean \pm s.d. and percentages, respectively. Two-related-sample tests of Wilcoxon signed-rank test, Paired Samples $t$-test and $\chi^{2}$-test were used for analysis. Effects nominally significant at $P<0.05$ are cited.

This study was approved by the local ethic committee of the institute (2009NL013). A written and informed consent was obtained from each patient after explaining the objectives of the study and the possible side effects. We certify that all applicable institutional and governmental regulations concerning the ethical use of human volunteers were followed during the course of this research.

\section{RESULTS}

Before injection, there were 57 episodes of UTI, however, the episodes decreased to 32 after injection. Accordingly, the overall rates of UTI were $1.39 \pm 1.36$ and $0.78 \pm 0.96$ episodes per patient over 6 months for before and after injection, respectively. The overall UTI frequency had the tendency to decrease in patients who developed two or more UTI before injection, while the patients who did not develop UTI increased after injection (Figure 1), but from the longitudinal perspective, the UTI frequency had the tendency to decrease in patients who developed once or more UTI before injection (Table 2). Two-related-sample tests of Wilcoxon signed-rank test showed that there was significantly difference between before and after injection in the incidence of UTI $(Z=-2.271, P=0.023)$. The overall UTI included one episode of acute epididymitis for two patients before injection, others were acute pyelonephritis. Antibiotic durations for the two episodes of acute epididymitis were 18 and 21 days, respectively; mean antibiotic duration for acute pyelonephritis was $6.2 \pm 1.6$ days.

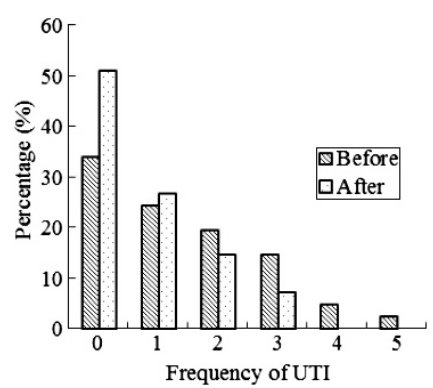

Figure 1 Changes of percentages of groups with different UTI frequency before and after injection in $41 \mathrm{SCl}$ patients.

Table 2 Longitudinal changes of UTI frequency after injection in $41 \mathrm{SCl}$ patients

\begin{tabular}{|c|c|c|c|c|c|c|}
\hline \multirow[t]{2}{*}{$\begin{array}{l}\text { UTI frequency } \\
\text { before injection } \\
\text { (patient's no.) }\end{array}$} & & & & & \\
\hline & 0 & 1 & 2 & 3 & 4 & 5 \\
\hline $0(14)$ & $9(64.3 \%)$ & 3 (21.4\%) & 2 (14.3\%) & 0 & 0 & 0 \\
\hline $1(10)$ & 7 (70.0\%) & 0 & $1(10.0 \%)$ & 2 (20.0\%) & 0 & 0 \\
\hline $2(8)$ & 2 (25.0\%) & $6(75.0 \%)$ & 0 & 0 & 0 & 0 \\
\hline $3(6)$ & 2 (33.3\%) & 0 & $3(50.0 \%)$ & 1 (16.7\%) & 0 & 0 \\
\hline $4(2)$ & 1 (50\%) & 1 (50\%) & 0 & 0 & 0 & 0 \\
\hline $5(1)$ & 0 & $1(100 \%)$ & 0 & 0 & 0 & 0 \\
\hline
\end{tabular}

Abbreviations: SCI, spinal cord injury; UTI, urinary tract infection.

After injection, the episode of UTI decreased in $23(56.1 \%)$ patients, increased in $8(19.5 \%)$ patients and did not change in 10 (24.4\%) patients (Table 2 ). The mean maximum cystometric capacity increased significantly from $238.0 \pm 72.1,278.8 \pm 75.4,225.0 \pm 61.2 \mathrm{ml}$ before injection to $350.1 \pm 58.4,378.0 \pm 66.1,310.0 \pm 61.0 \mathrm{ml}$ in the UTI decreased, no change, increased patients after injection $(P<0.01)$, while the mean maximum detrusor pressure during filling decreased significantly from $54.6 \pm 16.0,49.7 \pm 14.5,64.5 \pm 14.5$ $\mathrm{cmH}_{2} \mathrm{O}$ to $28.2 \pm 15.1,20.0 \pm 12.7,39.6 \pm 16.7 \mathrm{cmH}_{2} \mathrm{O}(P<0.01)$, respectively. Before injection, all 41 patients had detrusor overactivity, however, this number decreased to 13, 5 and 6 in the UTI decreased, no change, increased patients, respectively. In the 24 patients of detrusor overactivity after injection, although the episodes of UTI had the tendency to decrease after injection $(1.46 \pm 1.47$ vs $1.04 \pm 1.08)$, there was no significant difference $(Z=-0.996, P=0.319)$. However, in the 17 patients of detrusor normo-active after injection, the episodes of UTI decreased significantly from $1.29 \pm 1.21$ before injection to $0.41 \pm 0.62$ after injection $(Z=-2.434, P=0.015)$. A further analysis showed that the mean maximum detrusor pressure decreased more significantly in patients of detrusor normo-active than in patients of detrusor overactivity (35.4 \pm 12.2 vs $20.9 \pm$ $7.9 \mathrm{cmH}_{2} \mathrm{O}, P=0.000$ ). The changes of clinical and urodynamic parameters after injection are presented in Table 3.

Causal organisms of UTI in the 6 months before and 6 months after detrusor BoNTA injection were analyzed (Table 4). Escherichia coli, Enterococcus faecalis and Klebsiella pneumonia were the dominant bacteria for UTI before and after injection. The rate for E. faecalis, Pseudomonas aeruginosa, Proteus mirabilis, Staphylococcus aureus and S. epidermidis caused UTI decrease after injection, while E. coli, K. pneumonia and Acinetobacter cloacae caused UTI increase. 
Table 3 Changes in clinical and urodynamic parameters in $\mathrm{SCl}$ patients with detrusor BoNTA injection

\begin{tabular}{|c|c|c|c|}
\hline Variable & Before injection & After injection & P-value \\
\hline \multicolumn{4}{|l|}{ Clinical parameters } \\
\hline $\begin{array}{l}\text { Mean number of catheteri- } \\
\text { zations/24 h }\end{array}$ & $4.0 \pm 1.2$ & $4.7 \pm 0.8$ & 0.001 \\
\hline $\begin{array}{l}\text { Mean urine volume/cathe- } \\
\text { terization }(\mathrm{ml})\end{array}$ & $204.2 \pm 58.0$ & $365.8 \pm 63.0$ & 0.000 \\
\hline \multicolumn{4}{|c|}{ Incontinence between sterile intermittent catheterizations } \\
\hline Yes & 41 & 12 & 0.000 \\
\hline No & 0 & 29 & \\
\hline \multicolumn{4}{|l|}{ Urodynamic parameters } \\
\hline $\begin{array}{l}\text { Mean maximum detrusor } \\
\text { pressure }\left(\mathrm{cmH}_{2} \mathrm{O}\right)\end{array}$ & $55.3 \pm 15.8$ & $28.4 \pm 15.9$ & 0.000 \\
\hline $\begin{array}{l}\text { Mean maximum cystometric } \\
\text { capacity }(\mathrm{ml})\end{array}$ & $245.4 \pm 72.0$ & $349.1 \pm 63.4$ & 0.000 \\
\hline $\begin{array}{l}\text { Mean bladder compliance } \\
\left(\mathrm{ml} \mathrm{cmH} \mathrm{CO}^{-1}\right)\end{array}$ & $4.9 \pm 2.3$ & $19.1 \pm 16.0$ & 0.000 \\
\hline \multicolumn{4}{|l|}{ Detrusor overactivity } \\
\hline Yes & 41 & 24 & 0.000 \\
\hline No & 0 & 17 & \\
\hline Reflux & None & None & \\
\hline Bladder stone & None & None & \\
\hline \multicolumn{4}{|c|}{ Urodynamic parameters for detrusor overactivity after injection $(n=24)$} \\
\hline $\begin{array}{l}\text { Mean maximum detrusor } \\
\text { pressure }\left(\mathrm{cmH}_{2} \mathrm{O}\right)\end{array}$ & $58.1 \pm 18.1$ & $37.2 \pm 14.7$ & 0.000 \\
\hline $\begin{array}{l}\text { Mean maximum cystometric } \\
\text { capacity }(\mathrm{ml})\end{array}$ & $218.1 \pm 51.8$ & $318.4 \pm 48.3$ & 0.000 \\
\hline \multicolumn{4}{|c|}{ Urodynamic parameters for normo-active detrusor after injection $(n=17)$} \\
\hline $\begin{array}{l}\text { Mean maximum detrusor } \\
\text { pressure }\left(\mathrm{cmH}_{2} \mathrm{O}\right)\end{array}$ & $51.4 \pm 11.2$ & $16.1 \pm 6.8$ & 0.000 \\
\hline $\begin{array}{l}\text { Mean maximum cystometric } \\
\text { capacity }(\mathrm{ml})\end{array}$ & $284.0 \pm 80.0$ & $392.4 \pm 57.5$ & 0.000 \\
\hline
\end{tabular}

Abbreviations: BoNTA, botulinum toxin $\mathrm{A}$; SCl, spinal cord injury.

\section{DISCUSSION}

Identical to previous reports, ${ }^{6-9}$ our study found that detrusor BoNTA injection was an effective treatment for NDO and incontinence after failure or resistance to anticholinergic drugs. Our study also found detrusor BoNTA injection significantly decreased UTI in patients with NDO caused by SCI, which demonstrates that detrusor BoNTA injection might have a preventive role for UTI in those people. However, there are conflicting reports about whether detrusor BoNTA injection could inhibit UTI in patients with NDO. Game et al. ${ }^{10}$ reported that detrusor BoNTA injection significantly decreased the incidence of symptomatic UTI in patients with NDO caused by SCI or multiple sclerosis, but Herschorn et al. ${ }^{8}$ covered the incidence of UTI was unchanged in those types of patients, while Cruz et al. ${ }^{7}$ demonstrated the incidence of UTI was unchanged in SCI patients and increased in multiple sclerosis patients after BoNTA detrusor injections.

Several reasons were responsible for the different conclusions. First, because of loss of sensation, NDO patients do not have the common symptoms of UTI, such as frequency, urgency and dysuria; sometimes chills and fever may be the only objective symptoms. ${ }^{16}$ Second, the definitions of UTI are different in different reports. Game et al.
Table 4 Causal organisms of UTI in the 6 months before and 6 months after injection

\begin{tabular}{lcc}
\hline Organisms & Before injection (\%) & After injection (\%) \\
\hline Escherichia coli & $28 / 57(49.1)$ & $20 / 32(62.5)$ \\
Enterococcus faecalis & $9 / 57(15.8)$ & $2 / 32(6.3)$ \\
Klebsiella pneumonia & $7 / 57(12.3)$ & $6 / 32(18.8)$ \\
Pseudomonas aeruginosa & $5 / 57(8.8)$ & $1 / 32(3.1)$ \\
Proteus mirabilis & $3 / 57(5.3)$ & $1 / 32(3.1)$ \\
Staphylococcus aureus & $3 / 57(5.3)$ & 0 \\
Acinetobacter cloacae & $1 / 57(1.8)$ & $2 / 32(6.3)$ \\
Staphylococcus epidermidis & $1 / 57(1.8)$ & 0
\end{tabular}

Abbreviation: UTI, urinary tract infection.

focused on clinical presentations and bacteriuria (symptomatic UTI), ${ }^{10}$ while Herschorn et al. ${ }^{8}$ focused on bacteriuria and Cruz et $a .^{7}$ did not indicate the standard of UTI. In our study, the definition of UTI is close to the standard of Game et al., but we emphasized fever for UTI. Third, the study population is different. To eliminate confounding factors, we excluded patients with infectious predilections and chose male, sterile intermittent catheterization, traumatic SCI patients.

The reasons are unclear for the decreasing of UTI after detrusor BoNTA injection in NDO patients. High bladder pressure is a risk factor for renal failure and symptomatic UTI. ${ }^{3,13}$ It promotes vesicoureteral reflux and ischemic injury to the bladder walls, creating favorable conditions for infection. ${ }^{5}$ It is speculated that detrusor BoNTA injection induced inhibition of detrusor overactivity and decrease of detrusor pressure were responsible for the decrease of symptomatic UTI. ${ }^{10}$ An indirect evidence is that anticholinergic drug decreases symtomatic UTI by reducing detrusor pressure. ${ }^{17}$ In our study, the mean maximum detrusor pressure decreased significantly in the subgroup of detrusor normo-active compared with the subgroup of detrusor overactivity, meantime the decrease of UTI after injection was significant in the former subgroup while no significant in the latter subgroup, which demonstrates the preventive role of detrusor BoNTA injection for UTI is related to the reduced degree of maximum detrusor pressure.

Urine microorganism is the root of UTI. As bacteria that cause UTI have been found colonizing the urethra and perineal skin of male patients with SCI, ${ }^{18}$ improving incontinence and less usage of urine pads or condom-catheters after detrusor BoNTA injection might influence the microorganism's perineal colonization, thus change the urine microorganism and reduce the occurrence of UTI. Though our study found the rate of causal organisms of UTI changed after detrusor BoNTA injection, whether detrusor BoNTA injection influences the microorganisms in urine and UTI through improving incontinence needs more research.

Three months after injection, video-urodynamic investigation was done and 17 patients were found detrusor normo-active, including 14 patients who still used anticholinergics in them. It is difficult to distinguish the detrusor overactivity/normo-active before urodynamic investigation, so it may be beneficial to use anticholinergics for the patients before urodynamic investigation. Anticholinergics and BoNTA injection may have a synergistic effect in improving detrusor overactivity, as anticholinergic drug could decrease symtomatic UTI by reducing detrusor pressure, ${ }^{17}$ so we continued the anticholinergics after injection for the aim of the study. After injection, the catheterization frequency and volume/catheterization both increased, which does not mean diuresis postoperative, but it 
reflects urine leaking was more severe before injection. As the bladder capacity increased significantly and the urine leaking improved obviously after injection, some patients increased one or two times of catheterization to improving incontinence and keeping the perineal dryness.

\section{DATA ARCHIVING}

There were no data to deposit.

\section{CONFLICT OF INTEREST}

Dr Liao's work has been funded by China National Technology R\&G Program (2012BAI34B02) and National Natural Scientific Foundation of China $(81070607,81270847)$. Dr Jia, Dr Chen and Dr Sui declare no potential conflict of interest.

1 Ditunno JJ, Formal CS. Chronic spinal cord injury. N Engl J Med 1994; 330 550-556.

2 Montgomerie JZ. Infections in patients with spinal cord injuries. Clin Infect Dis 1997 25: 1285-1290; quiz 1291-1292.

3 D'Hondt F, Everaert K. Urinary tract infections in patients with spinal cord injuries. Curr Infect Dis Rep 2011; 13: 544-551.

4 Cardenas DD, Hooton TM. Urinary tract infection in persons with spinal cord injury. Arch Phys Med Rehabil 1995; 76: 272-280.

5 Siroky MB. Pathogenesis of bacteriuria and infection in the spinal cord injured patient Am J Med 2002; 113: 67S-79S.

6 Chen $\mathrm{CY}$, Liao $\mathrm{CH}$, Kuo HC. Therapeutic effects of detrusor botulinum toxin A injection on neurogenic detrusor overactivity in patients with different levels of spinal cord injury and types of detrusor sphincter dyssynergia. Spinal Cord 2011; 49: 659-664.
7 Cruz F, Herschorn S, Aliotta P, Brin M, Thompson C, Lam W et al. Efficacy and safety of onabotulinumtoxinA in patients with urinary incontinence due to neurogenic detrusor overactivity: a randomised, double-blind, placebo-controlled trial. Eur Urol 2011; 60 . 742-750.

8 Herschorn S, Gajewski J, Ethans K, Corcos J, Carlson K, Bailly G et al. Efficacy of botulinum toxin $\mathrm{A}$ injection for neurogenic detrusor overactivity and urinary incontinence: a randomized, double-blind trial. J Urol 2011; 185: 2229-2235.

9 Chen G, Liao L. Injections of botulinum toxin A into the detrusor to treat neurogenic detrusor overactivity secondary to spinal cord injury. Int Urol Nephrol 2011; 43: 655-662.

10 Game X, Castel-Lacanal E, Bentaleb Y, Thiry-Escudie I, De Boissezon X, Malavaud B et al. Botulinum toxin $A$ detrusor injections in patients with neurogenic detrusor overactivity significantly decrease the incidence of symptomatic urinary tract infections. Eur Urol 2008; 53: 613-618.

11 Maynard FJ, Bracken MB, Creasey G, Ditunno JJ, Donovan WH, Ducker TB et al. International standards for Neurological and Functional Classification of Spinal Cord Injury. American Spinal Injury Association. Spinal Cord 1997; 35 266-274.

12 Waites KB, Canupp KC, DeVivo MJ. Epidemiology and risk factors for urinary tract infection following spinal cord injury. Arch Phys Med Rehabil 1993; 74: 691-695.

13 Esclarin DRA, Garcia LE, Herruzo CR. Epidemiology and risk factors for urinary tract infection in patients with spinal cord injury. J Urol 2000; 164: 1285-1289.

14 Schafer W, Abrams P, Liao L, Mattiasson A, Pesce F, Spangberg A et al. Good urodynamic practices: uroflowmetry, filling cystometry, and pressure-flow studies. Neurourol Urodyn 2002; 21: 261-274.

15 Lose G, Griffiths D, Hosker G, Kulseng-Hanssen S, Perucchini D, Schafer W et al. Standardisation of urethral pressure measurement: report from the Standardisation Sub-Committee of the International Continence Society. Neurourol Urodyn 2002, 21: 258-260.

16 DeVivo MJ, Kartus PL, Stover SL, Fine PR. Benefits of early admission to an organised spinal cord injury care system. Paraplegia 1990; 28: 545-555.

$17 \mathrm{Kim}$ YH, Bird ET, Priebe M, Boone TB. The role of oxybutynin in spinal cord injured patients with indwelling catheters. J Urol 1997; 158: 2083-2086.

18 Gilmore DS, Schick DG, Young MN, Montgomerie JZ. Effect of external urinary collection system on colonization and urinary tract infections with Pseudomonas and Klebsiella in men with spinal cord injury. J Am Paraplegia Soc 1992; 15: 155-157. 